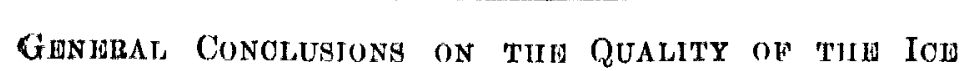
HROM a BACteriological poINT OW VIEW.

In making deductions from a bacteriological analysis of ice-water we must bear in mind that we cannot compare rirectly the results obtained with those obtained from an ordinary sample of water. We judge of the bacteriological purity of a water by $(a)$ the number of organisms that it contains and $(b)$ the variety of species present. From these data we are able to gather whether the water has recently come into relation with suspicious surroundings. Inasmuch, however, as not only the number of organisms but even the number of species in water is greatly diminished in the process of freezing, we should require much less evidence in this respect of the probable contrmination in the case of ice. Judging the specimens of ice above described by a standard based on the above considerations we should regard No. 1 as a very good sample of pure ice, Nos. 2 and 3 as bad, and Nos. 4,5 and 6 as of very fair quality.

The outcome of the whole inquiry is as follows

1. By far the greater proportion of ice supplied in London is natural (generally Norwegian). Of the specimens procured only one had been produced artificially, and this specimen gave indifferent results on chemical analysis, but results of an eminently satisfactory kind in the light of bacteriological inquiry, practically no development of colonies of organisms taking place on culture.

2. Two out of five specimens of ice imported into this country from Norway, whilst yielding a satisfactory chemical analysis, were decidedly bad according to bacteriological examination, the number of colonies of organisms counted on culture varying from 400 to 700 per cubic centimetre of the melted ice.

3. Three out of five specimens of imported ice, though furnishing no condemnatory evidence on chemical examination, yielded bacteriological results such as might under certain circumstances give rise to suspicion, though they may be regarded as of fairly good quality.

In the light of these results it is evident that when ice is intended for human consumption preference should be given to that produced by artificial means; but the water used for this purpose may not be satisfactory, and we would there fore point out the desirability of using only the condensed product of steam (distilled water) for this purpose-a pro duct, be it remarked, that must be free from disease-producing organisms. Natural ice as it is imported, though giving satisfactory results on chemical analysis, is not, in the majority of cases, entirely satisfactory from a bacteriological point of view; but it may be pointed out that a loophole of escape is afforded us by taking advantage of those chemical and physical phenomena in which change of state is con cerned in producing extreme cold: we refer to the production of ice artificially, and, bearing in mind the fact that ice is so frequently used in the sick room and for table purposes we strongly urge that it would be well if the means of obtaining a supply which we have indicated above-viz, the employment of freshly-distilled or sterilised water-could be generally adopted.

\section{THE NON-TRANSMISSION OF SMALL-POX BY VACCINE LYMPII}

By S. Mannington Cafrye, L R.C.P. Edin., M.R.C.S. Eng. LATE GOVERNMENT MEDICAL OFFICER FOR NEW SOUTH WALES.

THERE is no argument that the anti-vaccination enthusiast finds more useful in his contest with the obvious than hi assertion that it is possible to transmit disease tendencies and hereditary taint through the medium of lymph; and it has occurred to me that a record of an experience that helps to place any such possibility beyond the region of doubt will not be an absolute waste of time.

In the year $1881 \mathrm{I}$, then in practice at Wollongong, the third seaport of New South Wales, had business that necessitated my running down to Sydney. Business over, I made for the Australian Club in search of lunch and old friends. The first man to welcome me was Dr. Alleyne, who had been for forty years-i. e., since its birth-senior Government medical ufficer for the colony and had become quite a national institution. Dr. Alleyne wasa giant of the old order, eighty years of age,
$6 \mathrm{ft} .4 \mathrm{in}$. in height and as straight as a ram-rod. Greetino over, he removed his hat with a carefulness that did no surprise me, for $I$ knew it to be the receptacle of Gorem ment clespatches, urgent telegrams, news of ships waiting in the harbour for his sanction to come up and letters marke " "urgent," and most of these were unopened. The bottom that hat was never seen for the simple reason that the first second letter opened would summon him to some importan enuagement for the preceding day. In reply to my inguiry to how life was using him he pointed to his hat and gare deep grunt of despair, and I, walking to the table, took up and, at his request, opened the first letter that presente itself. It was marked "very important," twice underlines and it was important to this extent, that the contents Dr. Alleyne his life, altered the whole course of mine, anse the business of the colony as much as a civil war could han done and, lastly, resulted in the expenditure of $£ 270,000$ And yet the letter was a very brief one. It simply announce the fact that a certain medical man believed that he had di covered amongst his patients a case of confluentsmall-poz an requested the Government medical officer to see it with him a early as possible. The effect of this letter upon Dr. Allern was past describing, and to me, just from London wher small-pox was a matter of common occurrence, inexplicable He raved, stampel the floor and expressed his emotion forcibly. As the weeks flew past us with their ever-increasin rush of work, as public excitement rose to fever heat, an as street after street became deserted because a repor was abroad that some child had a pimple on its face it began to dawn upon me what small-pox meant to th unvaccinated community; but it was not until I wandered back alone from $\mathrm{my}$ old friend's funeral that I quite understood all that that letter meant to him. But to resume my narrative. At the urgent request of Dr. Allepn I saw the case for him. The consultation conld not be truthfully spoken of as at the "bedside," for the gentl man under whose care the patient was inspected him through a large lens used for the purpose of examining photographs and exposed one eye only round the cornes the door to the risk of infection. It was confluent small.por and thenceforth I had charge of the epidemic with orders to stamp it out at any cost. It would be impossible bere to give any idea of the extreme measures resorted to. With the help of Dr Higham Hill I burnt down terraces, white washed the insides of pianos, carbolised tons of sugar, te and grocery stores, and sent patients with temperatures $104^{\circ}$ across the harbour to the quarantine station in an open boat and in the middle of the night. It was at the quarantin station that the incident to which I am about to refer occurred. I had in my division of the ground some fort "suspects"-i.e., people who had been removed from infected houses, but not themselves suffering from the disease-and on the second day after my arrival the order came to vaccinate everybody under my care. New South Wales bas no lar enforcing vaccination, and the whole community may be divided into three classes : a few-very few-who submit to the operation from the belief in its efficacy, the rest being equally divided into two parts-first, the careless, who are unvaccinated because in the fearful hurry of colonial life there has been no time to bother about it, the rest being rampan anti-vaccinationists, cursed with the little knowledge that is the badge of all their tribe. Therefore, when the order tas issued for all to be at my hut "by ten to-morrow" that Imight vaccinate them, a thrill of excitement and a whisper of mutim ran through the settlement. In obedience to the firt instincts of a young democracy a public meeting was sum. moned and a shoemaker of great verbosity was invited to the chair; the meeting lasted the whole afternoon, and the diret outcome of it was that a resolution, formally drawn up and signed on behalf of the meeting by the chairman, was pre sented to me. Of the contents of this document I onl remember that it entered very deeply into the scientific inaccuracy of the whole theory of vaccination and the gros interference with the liberty of the subject, and ended with distinct refusal to submit to the operation. But a threat of prolonged detention and some tact brought about a compot mise; after another meeting that lasted well into the niobt the people consented to be vaccinated if the lymph used was taken from a child who had been brought down the previous day-a fine, healthy child, with a clean skin and of good parentage To this I consented and on the following day the terrible ordal was gone through, I including myself amongst those operated upon. The next morning I was sent for very early to see the child from whom the lymph had been taken. I found bs 
suffering from most severe premonitory symptoms of smallpor in two days she was covered with a confluent rash and in sir days she was dead, and I, standing on the mound of sand that had been the shoemaker's "chair" at the antiraccination meeting, read the burial service over the body. The faneral over, I and my friend the shoemaker-friends now by force of a common danger-walked the beach and talked of death. I do not hesitate to say that I fully shared in the fear that saddened the whole community, as also in the common danger. If there was any truth whatever in this theory of transmission there was no escape for us; this child at the very time the lymph was taken from her was nearing the end of her period of incubation. If raccine lymph could convey any other disease than raccinia it ought to be variola, and therefore what hope had we? The most heartless of the readers of THE LANCETif such a term will apply to any member of our profession-must admit that in a foreign land, away from all friends and home comforts and with a certainty (so I construed it) of a borrible death impending, my lot until the prescribed time had passed was anything but an enviable one. This sense of fear, which so overwhelmed us that the commonest greetings were neglected, was in a great measure due to the fact that we were the outcasts of a community and treated very much as were the lepers of old; we were without occupation and often without proper nourishment. On the day after the funeral I-finding that the wildest rumours were afloat and that wives and husbands were endeavouring to suck the poison from each other's arms, whilst some were openly arowing that suicide were better than this sleepless suspense-summoned the whole of them to my hut. I examined their arms and found that out of thirty-nine vaccinated only one had failed to take. It was that of a member of the same family to which the child belonged from whom we were all vaccinated; his marks on this (the fifth) day had almost disappeared, a fact that gave him infinite satisfaction. In the other thirty-eight cases the pustules were running the ordinary course with this marked exception that in every case the areola of inflammation was very exaggerated, as also was the swelling of the limb--so much so that many of us wore slings and all have the record of that horrible time written in tremendous cicatrices. The boy whose arm did not take caug ht small-pox some e'ght or ten days afterwards and (as was the case with all my patients who had been vaccinated in early youth as he had been) it ran a very mild and stereotyped course. As the number vaccinated from one arm is probably very unusual I would like to explain the system I followed throughout the epidemic-a system rendered necessary by the scarcity of lymph. I first very carefully punctured each postule and then drew up the lymph as it escaped into a very small glass tube reduced ts a flat narro $\pi$ opening at the end, but dilated just above into a bulb to receire it To this lymph I added one-third glycerine and one-third distilled water.

The moral of this record is, I think, too obtious to be dilated upon. Here was a child who caught small-pox and was vaccinated during the earlier stages of incubation, the disease being in no way influenced by it; here were also close upon forty people vaccinated from this child within twenty-four hours of the appearance of the eruption, only one of them failing to take, and he later had an attack of small-pox which ran the ordinary mild course seen in those well vaccinated in early life, whilst the others, but for the severity of the resultant pustule, might have been inoculated with the purest lymph ever used.

\section{THE ASSOCIATION OF FELLOWS OF THE ROYAL COLLEGE OF SURGEONS OF ENGLAND.}

$A$ rERY full and important meeting of the Committee of the Association of Fellows of the Royal College of Surgeons of England was held on July 19 th at 5 P.M. Mr. George Pollock, the President, occupied the chair. The minutes of the last meeting were read and confirmed. The hon. sec. read the following announcement, which had been sent out on a postcard to the members of the Committee for the purpose of convening the meeting :

The Association of Fellows of the Royal College of Surgeons of England. Important.

39, Welbeck-street, W., July 10th, 1893.

DEAR $\mathrm{StR}_{4}-\mathrm{A}$ meeting of the Committee of the Association of
36, Grosyenor-street, W., on Wednesday, July 19th, at 5 p.M., for the purpose of di cussing the future policy of the Asyociation in view of the surcess of the cundidates of the Association at the election on the 6th inst. To this meeting invitations are being issued to members of the Council of the College whose views are known to he favourable to the programme of reform adopted by the Association. It is earnesi 1 . hoped that you will be able to attend this combined meeting. anil you are requested kindly to intimate your intention with respect thereto on the accompanying reply postcard at your earliest convenience. Yours taithfully,

H. Percy Dunn, Hon. Secretary.

Letters to a similar effect were addressed to severa members of the council of the College. Favourable replies were received accepting the invitation of the Committee.

Letters of regret at their unavoidable absence were received from Mr. George Jackson (Plymouth), Mr. J. J. Purnell (Streatham), Mr. IBickersteth (Liverpool), Mr. Victor Horsley, Mr. William Square (Plymouth), Mr. G. F. Helm (Cornwall), Mr. Bruce Clarke and Mr. C. Steele (Bristol).

The following Fellows of the College having been duly proposed and seconded, were unanimously elected Members of the Association: Dr. Hugh Smith (Highgate), Dr. F. Churchill (London), Dr. Urban Pritchard (London), Dr. Ernest Arnold (Forest Hill), Mr. G. F. Blacker (London), Mr. Newland Pedley (London) and Dr. E. Deanesly (Wolverhampton).

The Hon. Secretary reported that he had not received any reply to his letter addressed to the President of the College conveying a copy of a resolution passed at the last annual meeting with reference to the meetings of Fellows. The following resolution, proposed by $\mathrm{Mr}$. T. Holmes and seconded by Mr. Gant, was unanimously passed: "That Mr. Dunn be asked to write to the Secretary of the College and inquire whether the letter to the President of the College had reached its destination and would be laid before the council; and, should the reply be in the negative, to send a fresh letter in the same terms with a request that it should be read to the council." A cordial vote of congratulation on their success at the recent election was passed to Mr. Macnamara and Mr. Mayo Robson. Mr. Macnamara was also congratulated on having been appointed one of the vice-presidents of the College for the ensuing year, this being the first occasion on which a member of the Association had been elected to any office of the kind. A vote of thanks was unanimously passed to Mr. A. 'T. Norton for coming forward as a candidate at the recent election in the interest of the Association and a hope was expressed that he would stand again next year.

The future policy of the Association was then discussed and various members of the committee and the members of the council present expressed their views in connexion therewith. It was unanimously resolred that the council of the College should be approached for the purpose of obtaining a new Charter embodying the points of reform advocated by the Association. It was further resolved that a sub-committee should be appointed to consider and report upon the special points which should be dealt with in the Charter, the report to be presented to the committee in October next. This corcluded the business of the meeting and the committee adjourned.

\section{CHOLERA.}

Cholera continues to prevail on the Continent and elsewhere, but there has happily not been much to chronicle this year indicative of its rapid spread or epidemic progress up to the present time. As we have already said, lowever, we are approaching the season when epidemic manifestations and outbreaks commonly occur, and it is consequently quite natural that sanitary authorities and public health bureaux should be in a state of what may be termed expectant attention. As regards tlie severe outbreak in Mecca, it appcars there has been some delay and difliculty about the sea transport of the pilgrims back to their own countries. All have probably by this time left Mecca and, except those who have died or been detained at El-Tor, are already making or about to make the return journey. Nine cases of cholera and eight deaths occurred in the quarantine hospital at El-'Tor from the 18th to the 20th inst., but the village in the vicinity was quite free from the disease, which is now nearly extinct at El-Tor also. Cholera is said to be prevalent in the region between the Yeman and the Hedjaz. According to a 